1 Department of Psychology, Kingston University London, United Kingdom

2 Department of Neuroscience, Psychology and Behaviour, University of Leicester, United Kingdom

3 Department of Psychology, Islamic University Gaza, Palestine

4 Department of Paediatrics and Interim Translational Research Institute (iTRI), Hamad Medical Corporation (HMC) and College of Health and Life Science (CHLS), Hamad Bin Khalifa University (HBKU), Doha, Qatar

Correspondence to: M Samara m.samara@kingston.ac.uk Cite this as: $B M J 2020 ; 371: \mathrm{m} 3155$ http://dx.doi.org/10.1136/bmj.m3155 Published: 19 November 2020

TOXIC STRESS AND PTSD IN CHILDREN

\title{
Children's prolonged exposure to the toxic stress of war trauma in the Middle East
}

Conflict leads to toxic stress and health problems in childhood and beyond. Long term investment in evidence informed mitigation strategies is needed to end the devastating cycles of violence, write Muthanna Samara and colleagues

\section{Muthanna Samara, ${ }^{1}$ Sara Hammuda, ${ }^{1}$ Panos Vostanis, ${ }^{2}$ Basel El-Khodary, ${ }^{3}$ Nader Al-Dewik ${ }^{1}, 4$}

Violent political conflict has had a devastating effect on the physical and mental health of children in the Middle East (box 1). ${ }^{1}$ Many have been killed or injured. Many have been displaced, including 2.5 million Syrian child refugees. ${ }^{2}$ Conversely, Palestinian children under blockade in the Gaza Strip cannot escape even to relative safety. ${ }^{3}$

\begin{abstract}
Box 1: A century of political violence
The Middle East has seen several wars since the second world war-between Arab states and Israel, between 1948 and 1982; the Lebanese Civil War, from 1975 to 1990; wars in Iraq beginning in 1980 and with continuing unrest to the present day; the invasion of Kuwait in 1990; and the North Yemen Civil War, from 1962 to 1970. In late 2010, anti-government protests throughout the Middle East gave rise to the so called Arab Spring. Subsequent Libyan, Syrian, and Yemeni civil wars have been violent and prolonged. In addition, Palestinians in the Gaza Strip have experienced three wars in the past 12 years and have been living under a blockade since 2007.
\end{abstract}

Yemen's dire situation has triggered the world's biggest food security emergency and the largest recorded cholera epidemic. ${ }^{4}$ Children in conflict settings may lack access to water and experience bombing, loss of their home, and the injury or death of loved ones. ${ }^{5}{ }^{6}$ Sexual exploitation and abduction can proliferate when rule of law collapses. ${ }^{1}$ The effects of poverty and destroyed healthcare and schools can persist long after violence has ceased.

The threat of harm intensifies exposure to psychological trauma. ${ }^{1}$ Continuous exposure to trauma is associated with mental health problems including post-traumatic stress disorder (PTSD) ${ }^{7}$, emotional dysregulation, depression, and suicidal thoughts or behaviors. ${ }^{8}$

Toxic stress, when children experience strong, frequent, or prolonged adversity without adequate adult support. ${ }^{1910}$ can disrupt development of the brain and other organs and increase psychopathology as well as cognitive and emotional impairment. ${ }^{10} 11$ Effects are likely to persist into adulthood even after violence stops. Prompt identification and evidence based treatment of serious psychopathology can help. ${ }^{12}$

Children must be supported in healing from the effect of toxic stress to break the cycle of violence in which the next generation struggles to rebuild society after the trauma of war. ${ }^{1}$ But a focus on the short term effect of war means scant attention has been paid to longer term mental health support. A cohesive effort is needed among policy makers, humanitarian agencies, and health services in the region to increase resilience and prevent escalation in mental and physical health problems, and to advocate for security and health. ${ }^{13}$

\section{Toxic stress and mental health}

Children in armed conflict areas in the Middle East experience high rates of mental disorders, including PTSD, depression, anxiety, behavioral problems, and attention deficit hyperactivity disorder, as well as functional impairment. ${ }^{14}$ Worldwide, as many as one in five children and adults affected by conflict may experience mental ill health, compared with a mean global prevalence of one in $14 \cdot{ }^{15}$

Children in conflict areas are also at increased risk of suicide ideation, enuresis, nightmares, hypervigilance, grief, separation anxiety disorder, phobia, stuttering, stereotypic movements, refusal to attend school, learning disabilities, conduct disorders, aggression, and feeding disorders in infancy or early childhood.

These conditions impair children's ability to engage in daily life, to focus and perform in school, to form relationships and attachments, and to feel safe. ${ }^{16-23}$ Multiple exposures to violence cumulatively increases the risks. 222425

Without early intervention, these mental health problems are likely to continue into adulthood and to predict adverse outcomes. Untreated adults who experienced adverse childhood experiences may carry 12 times the risk for alcoholism, drug misuse, depression, and suicide attempts. They are also more likely to have physical health conditions, including heart disease, cancer, chronic lung or liver disease, and skeletal fractures. ${ }^{26}$

Young Kuwaiti adults' educational and occupational outcomes, for example, were adversely affected by exposure to war trauma a decade before..$^{27-29}$ Boys with greater exposure were less likely to pursue further education and more likely to have post-traumatic stress, poor sleep quality, high body mass index, and poor self-reported health in adulthood. 


\section{Mediating factors in toxic environments}

Children's risk of poor mental health is mediated by genetic, familial, societal, and environmental factors, which influence their development in a toxic environment. ${ }^{30-32}$ Effects are subsequently transmitted through biological, psychological, familial, economic, and societal pathways. ${ }^{33-35}$ In war environments, good parenting, relationships with teachers, social networks, and healthcare systems are also affected by trauma and toxic stress and may be less protective or even harmful. ${ }^{25} 36$

Children with traumatized parents may be at increased risk of poor mental health outcomes, particularly without social support. 33-35 Postwar trauma among Palestinian fathers, ${ }^{37}$ and arrest of Kuwaiti fathers during the war, ${ }^{27-29}$ for example, were related to increased mental health problems, avoidance behaviors, and attachment insecurity among their offspring.

Children born after conflict stops can also be affected. Intergenerational transmission has been observed in increased rates of mental illness in the children of Holocaust survivors, for example. ${ }^{38}$

Poverty that persists after violence stops affects children directly and indirectly through the parent-child relationship, aggravating toxic stress responses. ${ }^{3940}$ In addition, parents worrying about daily survival can become less nurturing and more aggressive towards their children. ${ }^{25} 3941$

\section{Mental health services in the Middle East}

Health services in Middle Eastern countries are provided by governmental, commercial, and non-governmental organizations. Disruption to health services often continues even after violence stops, ${ }^{35}$ while demand for healthcare remains high. The Libyan system operates far below the needs of the population, for example, ${ }^{42}$ including mental health services. ${ }^{43}$ Retention and recruitment of staff in war contexts is especially difficult, for reasons including disruption to education systems (boxes 2 and 3). 35

\section{Box 2: Maternity services in Palestine}

Disruption to maternity services increases risks of health and birth complications. Delays caused by military checkpoints in Palestine, for example, were associated with more home births (8\% in 1999 and 33\% in 2002). 4445 Low birthweight and prematurity raise risks of long term adverse outcomes among children, including mental health and behavioral problems, eating problems, lower IQ, and poorer educational outcomes. 4647

\section{Box 3: Mental health services in Yemen}

Rates of mental health problems are much higher in Yemen than other countries in conflict. ${ }^{23}$ War, floods, epidemics, poverty, and water shortages have damaged healthcare and education systems, $48-50$ and they lack practitioners. ${ }^{4}$ An intervention among general practitioners was found to improve their performance in the emergency management of acute medical problems. ${ }^{51}$ WHO's Mental Health Gap Action Programme subsequently trained health and community workers to increase access to mental health services, 4 although these services have not been evaluated for use and effectiveness.

Although some national healthcare plans have started to recognize mental healthcare as essential (such as those in Iraq and Palestine), 5253 many Middle Eastern countries tend to lack mental health funding, resources, and workforce (fig 1). ${ }^{55}$ Psychosocial service providers face a lack of qualified, specialist staff, financial constraints, political conflict, and poor community awareness, a study of practitioners at refugee camps in the West Bank, Palestine, found. ${ }^{56}$

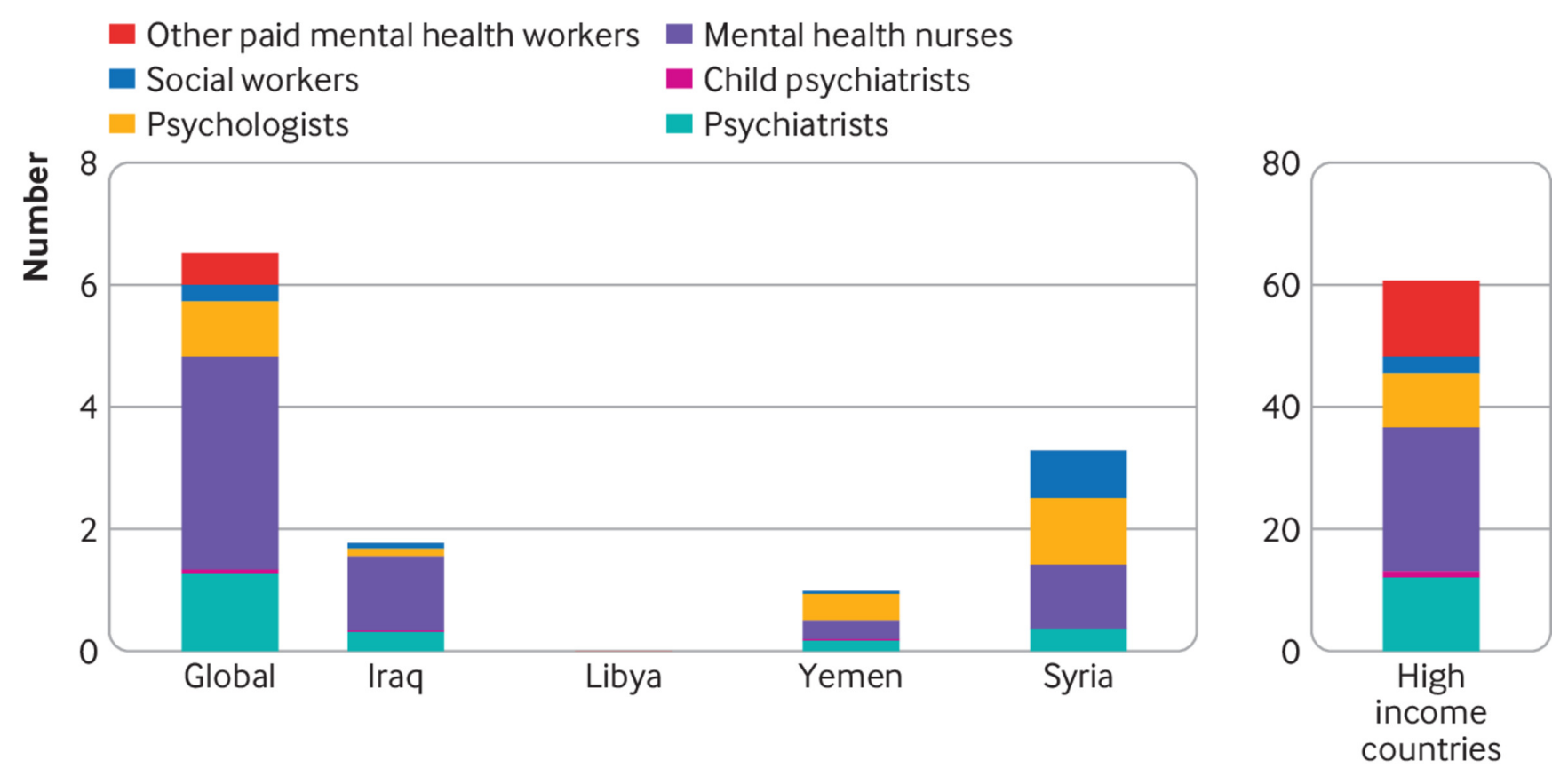

Fig 1| Mental health workforce (rate per 100000 population) in Middle Eastern countries with continuous conflict, compared with high income countries and global rate (where value is zero this is equal to zero or not reported). ${ }^{54}$

Additionally, stigma means people are less likely to access help that even when services are offered. Further obstacles may include inadequate transport and complex referral processes. Patients may seek alternatives, such as faith healers, as seen in Iraq. 57 


\section{Psychosocial interventions and service transformation}

Limited service provision and reluctance to access services must be at the forefront when designing mental health interventions for children in areas affected by conflict. A growing body of research from the Middle East and elsewhere shows the complexity of such children's needs, influenced by the interplay of multiple risk and protective factors. Overwhelming needs and paucity of specialist resources indicate the importance of multimodal interventions that maximize current resources and community strengths..$^{58}$

Evidence also shows the importance of tackling concurrent challenges that mental health services face in Middle Eastern cultures, such as stigma ${ }^{59}$; collective exposure to toxic stress of children, parents, communities, and professionals; limited contextualization and cultural adaptation of interventions; and constraints in infrastructure and staff competencies. ${ }^{60}$

First level response interventions should aim to strengthen children's coping strategies and resilience, life skills, and symptom management. Several psychoeducation and "trauma informed" (meaning that activities link to children's trauma exposure without intending for them to re-experience and re-process their experiences) programmes have shown promising results. ${ }^{61-63}$ These can include, body-mind interventions such as mindfulness that deal with physical and psychological presentations of distress (such as meditation, breathing techniques, guided imagery, and self-expression through words, drawings, and movement). Creative interventions emphasize interactive activities such as drama and music to help children build better relationships and improve resilience and wellbeing. ${ }^{64-68}$

Crucially, such programmes bypass many challenges faced by mental health services in the Middle East becasue they are low cost and can be delivered by paraprofessionals (or community volunteers), peer educators, teachers, social care or non-governmental organizations, who nevertheless require training, supervision, and links with mental health services. ${ }^{6}$

First level interventions are non-stigmatizing, as these can be provided to groups in schools, community, and religious centres. These contexts also solve access difficulties during conflicts and capitalize on feelings of belonging and comfort associated with their functions (especially religious forums). In Palestine, for example, school based intervention programmes including mind-body skills group programmes ${ }^{68}$ and teaching recovery techniques ${ }^{6970}$ showed success in decreasing various mental health problems among children and adolescents exposed to war trauma (box 4).

Box 4: A psychosocial school based support program in the Gaza Strip, Palestine

Wars in Palestine ${ }^{3}$ exposed children to trauma and mental health problems. ${ }^{25}$ After the 2014 war, teachers, social workers, and counsellors implemented a psychosocial support programme in all schools in the Gaza Strip. Parents were actively involved. Cognitive behavioral techniques included group psychoeducation, discussion of past traumatic experiences, physical exercises, cooperative games and drama. PTSD, other emotional, and somatic symptoms, as well as cognitive functional impairment, significantly decreased after the intervention. ${ }^{64}$

The second level of interventions can draw on contextualized frameworks such as trauma focused cognitive behavioral therapy (CBT), narrative exposure, and child centred therapy, and requires skilled mental health professionals ${ }^{71}$ lacking in Middle Eastern contexts. These should be offered to children whose symptoms continue after a resilience building approach. Long term investment in mental health will mean that more children can be targeted for intervention at this level. Ideally parents are involved, otherwise their own unresolved distress can adversely affect their children. Psychoeducation and parent-child dyadic psychotherapy or trauma focused CBT have been applied in war contexts (in Palestine, for example), but these should be adapted to the Middle Eastern culture and combined with social support. ${ }^{72}$ Coordination of services can offer adult mental health input.

Children, young people, and parents should actively be involved in the co-design and adaptation of interventions to ensure they are engaging and culturally acceptable. Interventions and capacity building should be framed in a stepped care service model (box 5). 7374

Box 5: A psychotherapy treatment in the Gaza Strip and the West Bank, Palestine

The occurrence and treatment of psychiatric disorders in the Gaza strip and the West Bank in Palestine were studied from 2005 to 2008 among patients older than 1 year. They were clinically assessed by a psychologist or a psychiatrist (supervised by a senior psychologist or psychiatrist) through a local mental health and counselling health network. Psychological care, consisting of individual, family, group, or dyad psychotherapy, ${ }^{8586}$ at home or in a consultation centre, was provided to the patients with diagnoses with PTSD, depression, or anxiety. The majority (79\%) had better symptoms through psychotherapy and around $30 \%$ required additional psychotropic medication. ${ }^{87}$

Digital interventions and staff training can be delivered in conflict affected areas using smartphones. ${ }^{75-77}$ These have been shown to be efficient in assessing, screening, evaluating, and intervening among children, adults, and practitioners in Middle Eastern countries, where smartphone use is common. ${ }^{78}$ Digital tools are relatively low cost and can be easily integrated to both response levels (box 6).

\section{Box 6: An online CBT intervention in Iraq}

$\overline{\text { Technology can help treat mental health problems in unstable areas that }}$ lack healthcare practitioners. ${ }^{75}$ An online CBT approach was developed to treat PTSD and other emotional problems in adults in Iraq. ${ }^{7579}$ Patients and trained therapists in Iraq, the Middle East, and Europe communicated through structured writing assignments submitted online. This form of intervention can improve symptoms of PTSD, anxiety, depressed mood, and grief across different cultures. ${ }^{76} 77$

\section{Recommendations for practice in the Middle East}

Firstly, in the immediate term, short courses should be provided for primary care professionals so they can detect and treat mental illness and refer to specialist services. Longer term, undergraduate medical curriculums need increased emphasis on mental health and formal training for practising medical practioners. ${ }^{80}$

Secondly, mental health professionals should train paraprofessionals, teachers, social workers, and other community workers in first level responses to strengthen children's coping strategies and resilience and to recognize those who need specialist interventions. Ideally, these professionals would themselves receive mental health support.

Thirdly, mental health professionals should be trained and supervized to implement level two interventions. Capacity building should be tailored to community and specialist levels, and an interdisciplinary context is needed to promote joint working, 
networks, and efficient use of resources. ${ }^{81}$ The particular social, cultural, and religious contexts in the Middle East should be taken into account.

Finally, a long term goal should be to upgrade and integrate mental health services across the health sector.

\section{Recommendations for research in the Middle East}

Research on child mental health, especially on interventions, has been underprioritized in Middle Eastern countries. Research examining specialist second tier interventions targeting children most at need specific to Middle Eastern contexts is currently lacking.

Policy makers and researchers should prioritize assessing prevalence, needs, and mechanisms to establish the amount of psychosocial support needed and shape planning. Accurate data on mental health resources, use, and expenditure in conflict affected Middle East settings are lacking. War torn populations are usually hard to access and screen for mental health disorders. More data are needed to evaluate national mental health intergration programmes such as those established with WHO's support.

Traditional paper based data collection is often difficult. Mobile phone based data collection, access to services, and interventions have had positive effects, such as in screening Palestinian children to enable timely intervention for children with psychopathology. ${ }^{82}$

Mental health literacy campaigns could assuage the concerns about stigma that deter participation in studies. ${ }^{83}$ Extending assessment to positive psychosocial functioning, coping strategies, and other indicators of resilience could also encourage participation.

Screening should use mixed methods to capture comprehensive psychosocial outcomes. Research tools and interventions may need culturally adaptation to Middle Eastern contexts, including language translation, piloting, culturally appropriate analogies, and focus group discussions with children, parents, teachers, and other stakeholders to co-design programmes and tools that match communities' needs. ${ }^{64}$ Tools and interventions should be contextualized to marginalized groups, including women and girls, disabled people, and developmentally delayed children.

Finally, research findings in the Middle East are mostly based on cross sectional studies, assessing mental health problems at one point in time. More longitudinal studies are needed, as they can assess the effects of prolonged trauma and toxic stress over time and generations.

\section{Key recommendations}

- Continuous and prolonged war trauma exposure in conflict areas in the Middle East affects children's development and mental health. Psychosocial interventions need to focus on building children's resilience and coping strategies and progress to more focused service provision for those who remain symptomatic

- The development of mental health problems can be mediated by multiple stressors, including parenting, parental wellbeing, and economic hardship. These need to be taken into account when designing multimodal interventions

- Instruments and interventions need to take into account the social, cultural, and religious contexts in the Middle East

- Research and practice barriers in the Middle East such as stigma, limited transportation, costs, and mental health services should be taken into consideration

- Middle Eastern countries that are affected by war and recurrent conflicts largely lack skilled mental health resources. Alternative plans could include training of paraprofessionals and frontline professionals on trauma focused, resilience, and coping strategies and interventions.

- Use of mobile mental health resources and digital technologies could be maximized

- The Middle East lacks planned, sufficient, and integrated mental health services. Policy makers should integrate mental health services building and development in the health care system plans and policies.

Contributors and sources: MS has expertise on developmental psychopathology investigating menta health in children of war, refugees, premature children, and bullying. SH is interested on the interplay between genetics and environment and its effects on the development of children. PV has developed and evaluated interventions and services for vulnerable children, especially in low income countries. $\mathrm{BE}-\mathrm{K}$ is interested in developmental psychopathology specially anxiety, PTSD, and depression in children of war. NA-D's expertise is on molecular and human genetics. MS initiated this article. All authors contributed to the conceptualization of the article. MS and SH wrote the first draft of the manuscript. All authors critically reviewed and approved the final manuscript. MS is the guarantor of this article.

Competing interests: We have read and understood BMJ policy on declaration of interests and have no interests to declare.

Provenance and peer review: Commissioned; externally peer reviewed.

This article is part of a series commissioned by The BMJ for the World Innovation Summit for Health (WISH) 2020. The BMJ peer reviewed, edited, and made the decisions to publish. The series, including open access fees, is funded by WISH.

MS was supported by the Qatar National Research Fund (QNRF) a member of Qatar Foundation Doha, Qatar, National Priority Research Programs (NPRP) under grant (NPRP 7-154-3-034). The authors thank QNRF for their support.

Save the Children International. The war on children: time to end grave violations against children in conflict. 2018. https://www.savethechildren.org.uk/content/dam/global/reports/education-andchild-protection/war_on_children-web.pdf.

2 Unicef. How to help Syria and its children. 2020. https://www.unicefusa.org/mission/emergencies/child-refugees-and-migrants/syria-crisis.

Palestinian Centre for Human Rights. Annual report. 2019.https://www.pchrgaza.org/en/wpcontent/uploads/2020/04/annual-report-2019-English.pdf.

4 Sanaa Centre for Strategic Studies. The impact of war on mental health in Yemen. 2017. http://sanaacenter.org/files/THE_IMPACT_OF_WAR_ON_MENTAL_HEALTH_IN_YEMEN.pdf. Shaw JA. Children exposed to war/terrorism. Clin Child Fam Psychol Rev2003:6:237-46. doi: 10.1023/B:CCFP.0000006291.10180.bd pmid: 14719636

6 Jordans MJ, Pigott H, Tol WA. Interventions for children affected by armed conflict: a systematic review of mental health and psychosocial support in low- and middle-income countries. Curr Psychiatry Rep 2016;18:9. doi: 10.1007/s11920-015-0648-z pmid: 26769198

7 Greenberg N, Brooks S, Dunn R. Latest developments in post-traumatic stress disorder: diagnosis and treatment. Br Med Bull 2015;114:147-55. doi: 10.1093/bmb/ldv014 pmid: 25904382

$8 \quad$ Khamis V. Posttraumatic stress disorder and emotion dysregulation among Syrian refugee children and adolescents resettled in Lebanon and Jordan. Child Abuse Negl 2019;89:29-39. doi: 10.1016/j.chiabu.2018.12.013 pmid: 30612072

9 Nooner KB, Linares LO, Batinjane J, Kramer RA, Silva R, Cloitre M. Factors related to posttraumatic stress disorder in adolescence. Trauma Violence Abuse 2012;13:153-66. doi: 10.1177/1524838012447698 pmid: 22665437

10 Shonkoff JP, Garner AS, Siegel BS, etalCommittee on Psychosocial Aspects of Child and Family HealthCommittee on Early Childhood, Adoption, and Dependent CareSection on Developmenta and Behavioral Pediatrics. The lifelong effects of early childhood adversity and toxic stress. Pediatrics 2012;129:e232-46. doi: 10.1542/peds.2011-2663 pmid: 22201156

11 Shonkoff JP, Richter L, van der Gaag J, Bhutta ZA. An integrated scientific framework for child survival and early childhood development. Pediatrics 2012;129:e460-72. doi: 10.1542/peds.2011-0366 pmid: 22218840

12 Nelson CA, Scott RD, Bhutta ZA, Harris NB, Danese A, Samara M. Adversity in childhood is linked to mental and physical health throughout life. BM/2020;371:m3048.

13 Inter-Agency Standing Committee. IASC guidelines on mental health and psychosocial support in emergency settings. 2007. https://www.who.int/mental_health/emergencies/9781424334445/en/

14 Dimitry L. A systematic review on the mental health of children and adolescents in areas of armed conflict in the Middle East. Child Care Health Dev 2012;38:153-61. doi: 10.1111/j.1365-2214.2011.01246.x pmid: 21615769

15 Charlson F, van Ommeren M, Flaxman A, Cornett J, Whiteford H, Saxena S. New WHO prevalence estimates of mental disorders in conflict settings: a systematic review and meta-analysis. Lancet 2019:394:240-8. doi: 10.1016/S0140-6736(19)30934-1 pmid: 31200992

16 Al-Jawadi AA, Abdul-Rhman S. Prevalence of childhood and early adolescence mental disorders among children attending primary health care centers in Mosul, Iraq: a cross-sectional study. BMC Public Health 2007;7:274. doi: 10.1186/1471-2458-7-274 pmid: 17910748 
17 Al-Hadethe A, Hunt N, Thomas S, Al-Oaysi A. Prevalence of traumatic events and PTSD symptoms among secondary school students in Baghdad. Eur J Psychotraumatol 2014;5:23928. doi: 10.3402/ejpt.v5.23928 pmid: 25413574

18 Summerfield D. War and mental health: a brief overview. BMJ2000;321:232-5. doi: 10.1136/bmj.321.7255.232 pmid: 10903662

19 Musisi S. Mass trauma and mental health in Africa. Afr Health Sci2004;4:80-2.pmid: 15477185

20 Attanayake V, McKay R, Joffres M, Singh S, Burkle F, JrMills E. Prevalence of mental disorders among children exposed to war: a systematic review of 7,920 children. Med Confl Surviv 2009;25:4-19. doi: 10.1080/13623690802568913 pmid: 19413154

21 Al-Eissa YA. The impact of the Gulf armed conflict on the health and behaviour of Kuwaiti children. Soc Sci Med 1995;41:1033-7. doi: 10.1016/0277-9536(94)00414-0 pmid: 8545664

22 Dubow EF, Boxer P, Huesmann LR, etal. Exposure to conflict and violence across contexts: relations to adjustment among Palestinian children. J Clin Child Adolesc Psychol 2010;39:103-16 doi: 10.1080/15374410903401153 pmid: 20390802

23 Al-Ammar F. Post-traumatic stress disorder among Yemeni children as a consequence of the ongoing war. 2018. https://carpo-bonn.org/wp-content/uploads/2018/03/10_carpo_brief_final.pdf.

24 Dubow EF, Boxer P, Huesmann LR, etal. Cumulative effects of exposure to violence on posttraumatic stress in Palestinian and Israeli youth. J Clin Child Adolesc Psychol 2012;41:837-44 doi: 10.1080/15374416.2012.675571 pmid: 22540411

25 El-Khodary B, Samara M. The relationship between multiple exposures to violence and war trauma, and mental health and behavioural problems among Palestinian children and adolescents. Eur Child Adolesc Psychiatry2020;29:719-31. doi: 10.1007/s00787-019-01376-8 pmid: 31352503

26 Felitti V], Anda RF, Nordenberg D, etal. Relationship of childhood abuse and household dysfunction to many of the leading causes of death in adults. The Adverse Childhood Experiences (ACE) Study. Am J Prev Med 1998;14:245-58. doi: 10.1016/S0749-3797(98)00017-8 pmid: 9635069

27 Hadi F, Llabre MM, Spitzer S. Gulf War-related trauma and psychological distress of Kuwaiti children and their mothers. J Trauma Stress 2006;19:653-62. doi: 10.1002/jts.20153 pmid: 17075916

28 Hadi F, Lai BS, Llabre MM. Life outcomes influenced by war-related experiences during the Gulf crisis. Anxiety Stress Coping 2014;27:156-75. doi: 10.1080/10615806.2013.832219 pmid: 24003829

29 Llabre MM, Hadi F. War-related exposure and psychological distress as predictors of health and sleep: a longitudinal study of Kuwaiti children. Psychosom Med 2009;71:776-83. doi: 10.1097/PSY.0b013e3181ae6aee pmid: 19592513

30 Bronfenbrenner U, Morris PA. The ecology of developmental processes. In: Handbook of child psychology: theoretical models of human development. Vol 1, 5th ed. Wiley, 1998: 993-1028.

31 Franke HA. Toxic stress: effects, prevention and treatment. Children (Basel) 2014;1:390-402. doi: 10.3390/children1030390 pmid: 27417486

32 Hornor G. Childhood trauma exposure and toxic stress: what the PNP needs to know. J Pediatr Health Care 2015;29:191-8. doi: 10.1016/j.pedhc.2014.09.006 pmid: 25697767

33 Weingarten K. Witnessing the effects of political violence in families: mechanisms of intergenerational transmission and clinical interventions. J Marital Fam Ther 2004;30:45-59. doi: 10.1111/j.1752-0606.2004.tb01221.x pmid: 14763208

34 Han M. Relationship among perceived parental trauma, parental attachment, and sense of coherence in Southeast Asian American College Students. J Fam Soc Work 2006;9:25-45doi: 10.1300/J039v09n02_02

35 Devakumar D, Birch M, Osrin D, Sondorp E, Wells JCK. The intergenerational effects of war on the health of children. BMC Med 2014;12:57. doi: 10.1186/1741-7015-12-57 pmid: 24694212

36 Salloum A, Stover CS, Swaidan VR, Storch EA. Parent and child PTSD and parent depression in relation to parenting stress among trauma-exposed children. J Child Fam Stud 2015;24:1203-12doi: 10.1007/s10826-014-9928-1

37 Palosaari E, Punamäki R-L, Qouta S, Diab M. Intergenerational effects of war trauma among Palestinian families mediated via psychological maltreatment. Child Abuse Neg/2013;37:955-68. doi: 10.1016/j.chiabu.2013.04.006 pmid: 23768956

38 Scharf M. Long-term effects of trauma: psychosocial functioning of the second and third generation of Holocaust survivors. Dev Psychopathol 2007;19:603-22. doi: 10.1017/S0954579407070290 pmid: 17459186

39 El-Khodary B, Samara M, Askew C. Traumatic events and PTSD among Palestinian children and adolescents: the effect of demographic and socioeconomic factors. Front Psychiatry 2020;11:4. doi: 10.3389/fpsyt.2020.00004 pmid: 32296346

40 Saile R, Ertl V, Neuner F, Catani C. Does war contribute to family violence against children? Findings from a two-generational multi-informant study in Northern Uganda. Child Abuse Negl 2014;38:135-46. doi: 10.1016/j.chiabu.2013.10.007 pmid: 24239222

41 El-Khodary B, Samara M. The mediating role of trait emotional intelligence, prosocial behaviour, parental support and parental psychological control on the relationship between war trauma, and PTSD and depression. J Res Pers 2019;81:246-56doi: 10.1016/j.jrp.2019.06.004

42 World Health Organisation (WHO). Annual report: Libya. 2019. https://www.humanitarianresponse.info/sites/www.humanitarianresponse.info/files/documents/files/who_libya_annual_report_2019.pdf.

43 Charlson FJ, Steel Z, Degenhardt L, etal. Predicting the impact of the 2011 conflict in Libya on population mental health: PTSD and depression prevalence and mental health service requirements. PLOS One 2012;7:e40593. doi: 10.1371/journal.pone.0040593 pmid: 22808201

44 Halla Shoaibi H. Childbirth at checkpoints in the occupied Palestinian territory. Abstract available at: https://download.thelancet.com/flatcontentassets/pdfs/palestine/palestine2011-4.pdf. 2011.
45 Marie M, Hannigan B, Jones A. Mental health needs and services in the West Bank, Palestine. Int J Ment Health Syst 2016;10:23. . doi: 10.1186/s13033-016-0056-8 pmid: 26981151

46 Samara M, Johnson S, Lamberts K, Marlow N, Wolke D. Eating problems at age 6 years in a whole population sample of extremely preterm children. Dev Med Child Neurol 2010;52:e16-22 doi: 10.1111/j.1469-8749.2009.03512.x pmid: 19832883

47 Samara M, Marlow N, Wolke DEPICure Study Group. Pervasive behavior problems at 6 years of age in a total-population sample of children born at $</=25$ weeks of gestation. Pediatrics 2008;122:562-73. doi: 10.1542/peds.2007-3231 pmid: 18762527

48 Nasser AA. Country profile Republic of Yemen. Asian disaster risk reduction center. 2017. https://www.adrc.asia/countryreport/YEM/yemen2009.pdf.

49 Burki T. Yemen health situation "moving from a crisis to a disaster." Lancet 2015;385:1609. doi: 10.1016/S0140-6736(15)60779-6 pmid: 25943803

50 Qirbi N, Ismail SA. Health system functionality in a low-income country in the midst of conflict: the case of Yemen. Health Policy Plan 2017;32:911-22. doi: 10.1093/heapol/czX031 pmid: 28402469

51 Abdul-Razik MS, Kaity AM, Banafaa NS, El-Hady GW. Disaster response in a civil war: Lessons on local hospitals capacity. The case of Yemen. Int J Healthc Manag 2019:1-8doi: 10.1080/20479700.2019.1616386

52 World Health Organisation (WHO). Building back better: sustainable mental health care after emergencies. WHO Press, 2013.

53 World Health Organisation. Country cooperation strategy for WHO and the Occupied Palestinian Territory 2017-2020. 2017. http://www.emro.who.int/pse/palestine-news/country-cooperationstrategy-for-who-and-the-occupied-palestinian-territory-20172020.html

54 World Health Organization. Mental Helath Atlas 2017.2018. https://www.who.int/mental_health/evidence/atlas/mental_health_atlas_2017/en/

55 Okasha A, Karam E, Okasha T. Mental health services in the Arab world. World Psychiatry 2012;11:52-4. . doi: 10.1016/j.wpsyc.2012.01.008 pmid: 22295010

56 Mahamid F, Veronese G. Psychosocial Interventions for third-generation Palestinian refugee children: current challenges and hope for the future. Int J Ment Health Addict2020. doi: 10.1007/s11469-020-00300-5

57 Younis MS, Lafta RK, Dhiaa S. Faith healers are taking over the role of psychiatrists in Iraq. Qatar Med J 2019;2019:13-13. doi: 10.5339/qmj.2019.13. pmid: 31819859

58 Vostanis P. Editorial: Global child mental health-emerging challenges and opportunities. Child Adolesc Ment Health 2017;22:177-8. doi: 10.1111/camh.12246 pmid: 32680416

59 Sewilam AM, Watson AMM, Kassem AM, etal. Suggested avenues to reduce the stigma of mental illness in the Middle East. Int J Soc Psychiatry 2015;61:111-20. . doi: 10.1177/0020764014537234 pmid: 24957595

60 Patel V, Saxena S, Lund C, etal. The Lancet Commission on global mental health and sustainable development. Lancet2018;392:1553-98. doi: 10.1016/S0140-6736(18)31612-X pmid: 30314863

61 Jordans MJD, Tol WA, Susanty D, etal. Implementation of a mental health care package for children in areas of armed conflict: a case study from Burundi, Indonesia, Nepal, Sri Lanka, and Sudan. PLoS Med 2013;10:e1001371. doi: 10.1371/journal.pmed.1001371 pmid: 23335863

62 Kalantari M, Yule W, Dyregrov A, Neshatdoost H, Ahmadi SJ. Efficacy of writing for recovery on traumatic grief symptoms of Afghani refugee bereaved adolescents: a randomized control trial. Omega (Westport) 2012;65:139-50. doi: 10.2190/OM.65.2.d pmid: 22953510

63 Panter-Brick C, Dajani R, Eggerman M, Hermosilla S, Sancilio A, Ager A. Insecurity, distress and mental health: experimental and randomized controlled trials of a psychosocial intervention for youth affected by the Syrian crisis. J Child Psychol Psychiatry 2018;59:523-41. doi: 10.1111/jcpp.12832 pmid: 28967980

64 El-Khodary B, Samara M. Effectiveness of a school-based intervention on the students' mental health after exposure to war-related trauma. Front Psychiatry 2020;10:1031. doi: 10.3389/fpsyt.2019.01031 pmid: 32273852

65 Gordon JS, Staples JK, Blyta A, Bytyqi M. Treatment of posttraumatic stress disorder in postwar Kosovo high school students using mind-body skills groups: a pilot study. J Trauma Stress 2004;17:143-7. doi: 10.1023/B:JOTS.0000022620.13209.a0 pmid: 15141787

66 Peltonen K, Qouta S, El Sarraj E, Punamäki R-L. Effectiveness of school-based intervention in enhancing mental health and social functioning among war-affected children. Traumatology 2012;18:37-46doi: 10.1177/1534765612437380

67 Layne CM, Saltzman WR, Poppleton L, etal. Effectiveness of a school-based group psychotherapy program for war-exposed adolescents: a randomized controlled trial. I Am Acad Child Adolesc Psychiatry 2008;47:1048-62. doi: 10.1097/CHI.0b013e31817eecae pmid: 18664995

68 Staples J, Abdel Atti J, Gordon J. Mind-body skills groups for posttraumatic stress disorder and depression symptoms in Palestinian children and adolescents in Gaza. Journal of Stress Manag. 2011;18:246-62. doi: 10.1037/a0024015

69 Barron IG, Abdallah G, Smith P. Randomized control trial of a CBT trauma recovery program in Palestinian schools. J Loss Trauma 2013;18:306-21doi: 10.1080/15325024.2012.688712

70 Qouta SR, Palosaari E, Diab M, Punamäki RL. Intervention effectiveness among war-affected children: a cluster randomized controlled trial on improving mental health. J Trauma Stress 2012;25:288-98. . doi: 10.1002/jts.21707 pmid: 22648703

71 Kangaslampi S, Garoff F, Peltonen K. Narrative exposure therapy for immigrant children traumatized by war: study protocol for a randomized controlled trial of effectiveness and mechanisms of change. BMC Psychiatry 2015;15:127 doi: 10.1186/s12888-015-0520-z pmid: 26081580 
72 El-Khani A, Ulph F, Peters S, Calam R. Syria: refugee parents' experiences and need for parenting support in camps and humanitarian settings. Vulnerable Child Youth Stud 2018;13:19-29doi: 10.1080/17450128.2017.1372651.

73 World Health Organization. Mental health: strengthening response. WHO, 2016.

74 Vostanis P, Eruyar S, Smit E, O’Reilly M. Development of child psychosocial framework in Kenya, Turkey and Brazil J. Child Serv (Mahwah NJ) 2019;14:303-16.

75 Wagner B, Schulz W, Knaevelsrud C. Efficacy of an internet-based intervention for posttraumatic stress disorder in Iraq: a pilot study. Psychiatry Res 2012;195:85-8. doi: 10.1016/j.psychres.2011.07.026 pmid: 21813187

76 Lange A, van de Ven JP, Schrieken B. Interapy: treatment of post-traumatic stress via the internet. Cogn Behav Ther 2003;32:110-24. doi: 10.1080/16506070302317 pmid: 16291543

77 Wagner B, Maercker A. A 1.5-year follow-up of an Internet-based intervention for complicated grief. J Trauma Stress 2007;20:625-9. doi: 10.1002/jts.20230 pmid: 17721955

78 Ashfaq A, Esmaili S, Najjar M, etal. Utilization of mobile mental health services among Syrian refugees and other vulnerable arab populations-a systematic review. Int J Environ Res Public Health 2020;17:E1295. . doi: 10.3390/ijerph17041295 pmid: 32085422

79 Knaevelsrud C, Brand J, Lange A, Ruwaard J, Wagner B. Web-based psychotherapy for posttraumatic stress disorder in war-traumatized Arab patients: randomized controlled trial. J Med Internet Res 2015;17:e71. . doi: 10.2196/jmir.3582 pmid: 25799024

80 World Health Organization. Building back better: sustainable mental health care after emergencies. WHO Press, 2013.

81 Vostanis P, O’Reilly M, Duncan C, Maltby J, Anderson E. Interprofessional training on resilience-building for children who experience trauma: stakeholders' views from six low- and middle-income countries. J Interprof Care 2019;33:143-52. doi: 10.1080/13561820.2018.1538106 pmid: 30358453

82 Hashemi B, Ali S, Awaad R, Soudi L, Housel L, Sosebee SJ. Facilitating mental health screening of war-torn populations using mobile applications. Soc Psychiatry Psychiatr Epidemiol 2017;52:27-33. . doi: 10.1007/s00127-016-1303-7 pmid: 27815623

83 Sewilam AM, Watson AMM, Kassem AM, etal. Suggested avenues to reduce the stigma of mental illness in the Middle East. Int J Soc Psychiatry 2015;61:111-20. . doi: 10.1177/0020764014537234 pmid: 24957595

84 Castro FG, Barrera M, JrMartinez CRJr. The cultural adaptation of prevention interventions resolving tensions between fidelity and fit. Prev Sci2004;5:41-5. doi: 10.1023/B:PREV.0000013980.12412.cd pmid: 15058911

85 Brems C. Psychotherapy: processes and techniques. Allyn and Bacon Publishers, 1998.

86 Schafer CE. Innovative psychotherapy: techniques in child and adoelscent therapy. Wiley, 1999.

87 Espié E, Gaboulaud V, Baubet T, etal. Trauma-related psychological disorders among Palestinian children and adults in Gaza and West Bank, 2005-2008. Int J Ment Health Syst 2009;3:21-21. doi: 10.1186/1752-4458-3-21 pmid: 19775427

This is an Open Access article distributed in accordance with the Creative Commons Attribution Non Commercial (CC BY-NC 4.0) license, which permits others to distribute, remix, adapt, build upon this work non-commercially, and license their derivative works on different terms, provided the original work is properly cited and the use is non-commercial. See: http://creativecommons.org/licenses/bync/4.0/. 